\title{
An expert opinion of the Association of Cardiovascular Interventions and the Working Group on Cardiovascular Pharmacotherapy of the Polish Cardiac Society related to the place of prasugrel in the prevention of cardiovascular events in patients with acute coronary syndromes
}

\author{
Marcin Barylski', Jacek Legutko², Maciej Lesiak3 , Stanisław Bartuś' ${ }^{4}$ Artur Mamcarz', \\ Beata Wożakowska-Kapłon ${ }^{6,7}$, Marek Grygier ${ }^{3}$, Wojciech Wojakowski ${ }^{8}$, Adam Witkowski $^{9}$ \\ Reviewers: Janina Stępińska ${ }^{10}$, Wiktor Kuliczkowski ${ }^{11}$ \\ 'Department of Internal Medicine and Cardiac Rehabilitation, Medical University of Lodz, Łódź, Poland \\ 2Department of Interventional Cardiology, Jagiellonian University Medical College, John Paul II Hospital, Kraków, Poland \\ ${ }^{3} 1^{\text {st }}$ Department of Cardiology, Poznan University of Medical Sciences, Poznań, Poland \\ ${ }^{4}$ Department of Cardiology and Cardiovascular Interventions, University Hospital, Kraków, Poland \\ ${ }_{5}^{5}{ }^{\text {rd }}$ Department of Internal Medicine and Cardiology, Medical University of Warsaw, Warszawa, Poland \\ ${ }^{6} 1^{\text {st }}$ Department of Cardiology and Electrotherapy, Voivodship Hospital Kielce, Poland \\ ${ }^{7}$ Collegium Medicum, Jan Kochanowski University, Kielce, Poland \\ ${ }^{8}$ Department of Cardiology and Structural Heart Diseases, Medical University of Silesia, Katowice, Poland \\ ${ }^{9}$ Department of Interventional Cardiology and Angiology, National Institute of Cardiology, Warszawa, Poland \\ ${ }^{10}$ Department of Intensive Cardiac Therapy, National Institute of Cardiology, Warszawa, Poland \\ ${ }^{11}$ Institute of Heart Diseases, Wroclaw Medical University, Wrocław, Poland
}

Correspondence to:

Prof. Marcin Barylski, MD, PhD,

Department of Internal Medicine and Cardiac Rehabilitation,

Medical University of Lodz,

Hallera 1, 90-647 Łódź, Poland,

phone: +48 603589082

e-mail: mbarylski3@wp.pl

Copyright by the Author(s), 2022

DOI: $10.33963 /$ KP.a2022.0006

Received:

December 13, 2021

Accepted:

December 29, 2021

Early publication date:

January 20, 2022

\section{A B S TR A C T}

Based on many randomized clinical trials, it can be concluded that dual antiplatelet therapy is one of the best-studied treatments in the field of cardiovascular medicine. For many years prasugrel and ticagrelor have been preferred inhibitors of the platelet $\mathrm{P} 2 \mathrm{Y} 12$ receptor in patients with acute coronary syndromes. These drugs enable faster, stronger, and more consistent inhibition of platelets and lead to better clinical outcomes than clopidogrel. The following document is an expert group opinion summarizing the latest knowledge in the field of antiplatelet therapy in the prevention of cardiovascular events in patients with acute coronary syndromes, with a special focus on prasugrel.

Key words: acute coronary syndromes, dual antiplatelet therapy, prasugrel

\section{INTRODUCTION}

Cardiovascular diseases (CVD) are the most common cause of death on a global scale, causing 17.9 million deaths annually and accounting for $31 \%$ of all deaths worldwide [1]. In Europe, over 4 million patients die from CVD every year, which accounts for as much as $45 \%$ of all deaths [2]. Among CVD, ischemic heart disease is the most common cause of death, accounting for around $20 \%$ of all deaths. Despite the improved prognosis in patients with acute coronary syndrome (ACS), and especially with acute myocardial infarction (AMI), which has been reported in recent years, this form of ischemic heart disease is still burdened with a high risk of death.

In Poland, about 160000 people fall ill with ACS every year. About $41 \%$ of these patients are diagnosed with unstable angina (UA), $28 \%$ with non-ST-elevated myocardial infarc- 
Table 1. Comparison of $\mathrm{P} 2 \mathrm{Y} 12$ receptor inhibitors

\begin{tabular}{|c|c|c|c|c|}
\hline & Clopidogrel & Prasugrel & Ticagrelor & Cangrelor \\
\hline Chemical group & Thienopyridine & Thienopyridine & $\begin{array}{l}\text { Cyclopentyl triazolopy- } \\
\text { rimidine }\end{array}$ & ATP analog \\
\hline Route of administration & Orally & Orally & Orally & Intravenously \\
\hline Binding to the $\mathrm{P} 2 \mathrm{Y} 12$ receptor & Irreversible & Irreversible & Reversible & Reversible \\
\hline Bioactivation & $\begin{array}{l}\text { Yes (prodrug, dependent } \\
\text { from CYP, two-step) }\end{array}$ & $\begin{array}{l}\text { Yes (prodrug, dependent } \\
\text { from CYP, single step) }\end{array}$ & No & No \\
\hline Dose & $\begin{array}{c}\text { Loading dose } \\
300 \text { or } 600 \mathrm{mg}, \\
\text { maintenance dose } 75 \mathrm{mg}\end{array}$ & $\begin{array}{l}\text { Loading dose } 60 \mathrm{mg} \text {, } \\
\text { maintenance dose } \\
10(5) \mathrm{mg}\end{array}$ & $\begin{array}{l}\text { Loading dose } 180 \mathrm{mg} \text {, } \\
\text { maintenance dose } \\
2 \times 90(60) \mathrm{mg}\end{array}$ & $\begin{array}{c}30 \mu \mathrm{g} / \mathrm{kg} \text { in an iv bolus, } \\
4 \mu \mathrm{g} / \mathrm{kg} / \mathrm{min} \text { by iv infusion } \\
\text { during } \mathrm{PCl}\end{array}$ \\
\hline The beginning of action & Delayed: $2-6$ hours & Fast: $0.5-4$ hours & Fast: $0.5-2$ hours & Instant: 2 minutes \\
\hline End of action & $3-10$ days & $5-10$ days & $3-4$ days & $0.5-1$ hour \\
\hline Operation delay & 5 days & 7 days & 5 days & Without significant delay \\
\hline Kidney failure & Without dose modification & Without dose modification & Without dose modification & Without dose modification \\
\hline Dialysis or $\mathrm{CrCl}<15 \mathrm{ml} / \mathrm{min}$ & Limited data & Limited data & Limited data & Limited data \\
\hline
\end{tabular}

Abbreviations: ATP, adenosine triphosphate; $\mathrm{CrCl}$, creatinin clearance; CYP, cytochrome P450; iv, intravenously; PCI, percutaneous coronary intervention

tion (NSTEMI), and 31\% with ST (ST-elevated myocardial infarction [STEMI]) [3]. According to the National Health Fund report, in 2018, percutaneous coronary intervention (PCI) was performed in $88.3 \%$ of STEMI patients, $64.4 \%$ of NSTEMI patients, and $47.8 \%$ of UA patients. In total, there were 56 thousand $\mathrm{PCls}$ for myocardial infarction and 13.4 thousand PCls for unstable angina [4]. Thanks to the implementation of these modern methods of treatment, it was possible to reduce the total hospital mortality to about $11 \%$ (6\% in patients treated invasively, 18\%-24\% in patients treated conservatively). However, there is still high mortality in the first 12 months after the onset of AMI, reaching $19 \%$ [5].

Platelet activation and aggregation play a key role in the pathophysiology of acute coronary syndrome, and the use of dual antiplatelet therapy (DAPT), including the combination of acetylsalicylic acid (ASA) and a platelet receptor P2Y12 inhibitor, is the basis of treatment in patients with ACS. Dual antiplatelet therapy not only reduces the risk of in-stent thrombosis but also reduces the incidence of spontaneous AMI [6]. The principles of antiplatelet therapy in patients with ACS that are currently used in Poland are based mainly on four documents: (1) the 2017 European Society of Cardiology (ESC) guidelines for the management of STEMI; (2) the updated ESC position on the use of dual antiplatelet therapy in coronary arterial disease prepared in collaboration with the European Association for Cardio-Thoracic Surgery (EACTS) in 2017; (3) the 2018 ESC and EACTS Guidelines for Myocardial Revascularization; and (4) the 2020 ESC Guidelines for the Management of NSTEMI [7-10]. They recommend that strong inhibitors of the $\mathrm{P} 2 \mathrm{Y} 12$ receptor (prasugrel, ticagrelor) are preferred in combination with ASA continuously for 12 months unless there are contraindications or an excessive risk of bleeding (recommendation class I, evidence level A). Unfortunately, in Poland, most patients with ACS still receive DAPT based on clopidogrel and ASA. The analysis of data on antiplatelet therapy in patients with STEMI enrolled in the national ORPKI registry between September 2015 and August 2016, including 19437 patients from 122 centers (immediate $\mathrm{PCl}$ in $94 \%$ of cases), showed that 31 centers did not use ticagrelor or prasugrel. The dominant P2Y12 inhibitor was clopidogrel (69\% of patients), with a high percentage of pre-hospital use (51.3\%). Ticagrelor was administered in $10.1 \%$ of patients ( $2.3 \%$ in the pre-hospital phase) and prasugrel in $1.1 \%$ of patients $(0.4 \%$ in the pre-hospital phase). Periprocedural conversion from clopidogrel to a strong inhibitor of the $\mathrm{P} 2 \mathrm{Y} 12$ receptor was also rare ( $2 \%$ for ticagrelor, $0.15 \%$ for prasugrel) [11]. Therefore, there is a pressing need for extensive discussion and education to significantly improve adherence to oral antiplatelet drugs in patients with ACS.

\section{CHARACTERISTICS OF P2Y12 PLATE RECEPTOR INHIBITORS}

In Poland, only oral inhibitors of the P2Y12 receptor are currently used: clopidogrel, prasugrel, and ticagrelor. Another drug that is registered and belongs to this group, but is not yet available, is cangrelor, which is intended only for intravenous use. Clopidogrel and prasugrel are prodrugs that require activation by the liver and their active metabolites irreversibly block the P2Y12 receptor. In contrast, ticagrelor and cangrelor are active drugs that block this receptor directly and reversibly. The characteristics of the key features of P2Y12 inhibitors are presented in Table 1.

Although clopidogrel is still the most used P2Y12 inhibitor in ACS therapy in patients treated with $\mathrm{PCl}$ in Poland, according to the current guidelines, it should only be an alternative to strong P2Y12 inhibitors (prasugrel or ticagrelor). It should be used if the above-mentioned drugs are unavailable, not tolerated, or contraindicated [7-10]. This is because, in randomized clinical trials in patients with ACS undergoing $\mathrm{PCl}$, clopidogrel was less effective than prasugrel (TRITON-TIMI study 38 [TRial to Assess Improvement in Therapeutic Outcomes by Optimizing Platelet InhibitioN with Prasugrel-Thrombolysis In Myocardial Infarction]) and ticagrelor (PLATO study [Platelet Inhibition and Patient Outcomes]). Clopidogrel is characterized by a significant 
variability of the pharmacodynamic response depending on several factors, also on genetic polymorphisms $[12,13]$.

Compared to clopidogrel, prasugrel enables faster, stronger, and more constant inhibition of P2Y12 platelet receptors. The TRITON-TIMI 38 study compared the efficacy and safety of prasugrel and clopidogrel in the prevention of cardiovascular events in patients with ACS undergoing $\mathrm{PCl}$ [12]. The primary endpoint was cardiovascular death and non-fatal myocardial infarction or a stroke. The primary endpoint was lower in patients treated with prasugrel than with clopidogrel (9.9\% vs. $12.1 \%$; hazard ratio [HR], 0.81; $95 \%$ confidence interval $[\mathrm{Cl}], 0.73-0.90 ; P<0.001)$ and was mainly due to the reduction in the incidence of myocardial infarctions (7.4\% vs. 9.7\%; HR, 0.76; 95\% Cl, 0.67-0.85; $P$ $<0.001)$. However, these clear clinical benefits were not found in people aged 75 years and older or in patients with low body weight $(<60 \mathrm{~kg}$ ) [12]. The incidence of major bleeding [defined by TIMI (thrombolysis in myocardial infarction), not associated with CABG (Coronary Artery Bypass Grafting), and fatal bleeding] was higher in prasugrel-treated patients than in clopidogrel-treated patients (2.4\% vs. $1,8 \% ; \mathrm{HR}, 1.32 ; 95 \% \mathrm{Cl}, 1.03-1.68 ; P=0.03$ ) [12].

In a subanalysis of patients with NSTEMI and UA, excluding patients at high risk of bleeding, patients using prasugrel experienced significant benefits in terms of ischemic events over patients taking clopidogrel (HR, $0.82 ; 95 \% \mathrm{Cl}, 0.73-0.93 ; P=0.002)$, without a significant increase in the risk of major bleeding complications (HR, $1.11 ; 95 \% \mathrm{Cl}, 0.77-1.60 ; P=0.57)$ [12]. In addition, in diabetic patients with ACS, prasugrel significantly reduced the incidence of the primary endpoint (12.2\% vs. $17.0 \%$; $\mathrm{HR}, 0.7 ; 95 \% \mathrm{Cl}, 0.58-0.85 ; P<0.001)$, without a significant increase in the incidence of bleeding complications $(2.5 \%$ vs. $2.6 \%$; $\mathrm{HR}, 1.06 ; 95 \% \mathrm{Cl}, 0.66-1.69 ; P=0.81)$. These results were obtained both in patients treated with insulin and untreated patients [14]. In patients with STEMI, there was a significant reduction in the incidence of stent thrombosis in the prasugrel group compared to the clopidogrel group (1.1\% vs. 2.4\%; HR, 0.48; 95\% Cl, 0.36-0.64; $P<0.001$ ) [15].

On the other hand, in the PLATO study, patients with ACS showed better results of ticagrelor compared to clopidogrel in reducing the composite ischemic endpoint: cardiovascular death, myocardial infarction or stroke $(9.8 \%$ vs. $11.7 \% ; P<0.001)$, and deaths from any cause $(4.5 \%$ vs. $5.9 \% ; P<0.001$ ) [13]. At the same time, no increased risk of serious bleeding was reported in patients treated with ticagrelor compared to patients treated with clopidogrel [13]. Details of the effect of prasugrel and tricagrelor on individual endpoints in comparison to clopidogrel in both studies are presented in Table 2.

The type of therapy and the duration of DAPT use in patients with coronary syndromes depend on the clinical situation (acute or chronic coronary syndrome), the treatment strategy (surgical or conservative), and the risk of bleeding (high or low risk of bleeding). These elements determine the choice of the antiplatelet drug and the timing of DAPT administration. When anticoagulation therapy is required, it further modifies antiplatelet therapy.

\section{COMPARISON OF PRASUGREL AND TICAGRELOR}

The PRAGUE-18 study (Comparison of Prasugrel and Ticagrelor in the Treatment of Acute Myocardial Infarction) compared the efficacy and safety of prasugrel and ticagrelor in STEMI patients undergoing $\mathrm{PCl}$. There were no statistically significant differences between the groups of patients receiving prasugrel or ticagrelor [16]. Therefore, it can be concluded from this study that prasugrel and ticagrelor are characterized by similar efficacy and safety in the studied group of patients. However, it should be emphasized that this study was characterized by low statistical power, because for financial reasons, in some patients during the follow-up, a strong P2Y12 inhibitor was changed to clopidogrel. Moreover, the study was terminated prematurely due to the lack of differences in the incidence of endpoints.

In 2019, the results of an international, multicenter, randomized phase IV study — ISAR-REACT 5 (The Intracoronary Stenting and Antithrombotic Regimen: Rapid Early Action for Coronary Treatment) — were announced. It compared the efficacy and safety of prasugrel and ticagrelor in preventing cardiovascular events in 4018 patients with ACS undergoing $\mathrm{PCl}$. The primary endpoint consisted of all-cause death, myocardial infarction (MI), and a stroke that occurred within one year of starting randomization [17].

The frequency of the primary endpoint (6.9\% vs. 9.3\%; $\mathrm{HR}, 1.36 ; 95 \% \mathrm{Cl}, 1.09-1.70 ; P=0.006)$ was significantly lower in prasugrel-treated patients than in ticagrelor-treated patients. The reduction in the frequency of primary endpoint in patients treated with prasugrel was mainly due to the reduction in the incidence of myocardial infarctions (3.0\% vs. 4.8\%; $\mathrm{HR}, 1.63 ; 95 \% \mathrm{Cl}, 1.18-2.25$ ), the information on the occurrence of the infarction was usually obtained via telephone conversations with the patient. However, there were no statistically significant differences in the incidence of major bleeding between the two groups: $4.8 \%$ vs. $5.4 \%$ in the prasugrel and ticagrelor groups, respectively $(\mathrm{HR}$, $1.12 ; 95 \% \mathrm{Cl}, 0.83-1.51 ; P=0.46)$ [17].

The results of the ISAR-REACT 5 study, surprising for many, were widely discussed in the cardiology world, triggering a lively discussion about the study protocol, the research methods used, the study population, and the method of conducting this clinical trial $[18,19]$.

Opponents of the ISAR-REACT 5 study argue that the study compared different antiplatelet treatment strategies, only partially complying with the ESC recommendations. They also indicate that the study was open-label, carried out only in two countries with a disproportionate number of recruiting centers ( 21 centers in Germany and 2 centers in Italy). The small proportion of non-compliant patients $(0.9 \%$ in the prasugrel group and $04 \%$ in the ticagrelor group) seems underestimated, as patients were controlled mainly by telephone ( $83 \%$ of contacts) or 
Table 2. Efficacy of prasugrel and ticagrelor vs. clopidogrel in terms of effect on individual endpoints in TRITON-TIMI 38 and PLATO [12-15]

\begin{tabular}{|c|c|c|c|c|c|c|c|c|c|}
\hline \multirow[t]{2}{*}{ Endpoint } & \multirow[t]{2}{*}{ Population } & \multicolumn{4}{|c|}{ Prasugrel } & \multicolumn{4}{|c|}{ Ticagrelor } \\
\hline & & $\begin{array}{c}\text { Event rate, } \% \\
\text { Prasugrel vs. } \\
\text { Clopidogrel }\end{array}$ & $\begin{array}{c}\text { ARR, } \\
\%\end{array}$ & $\begin{array}{c}\text { RRR, } \\
\%\end{array}$ & NNT & $\begin{array}{c}\text { Event rate, \% } \\
\text { Ticagrelor vs. } \\
\text { Clopidogrel }\end{array}$ & $\begin{array}{c}\text { ARR, } \\
\%\end{array}$ & $\begin{array}{c}\text { RRR, } \\
\%\end{array}$ & NNT \\
\hline \multirow{16}{*}{$\begin{array}{l}\text { Primary endpoint } \\
\text { (cardiovascular death, } \\
\text { non-fatal myocardial } \\
\text { infarction, or non-fatal } \\
\text { stroke) }\end{array}$} & Total & 9.9 vs. $12.1^{\mathrm{a}}$ & 2.2 & 18 & 46 & 9.8 vs. $11.7^{\mathrm{a}}$ & 1.9 & 16 & 53 \\
\hline & 1. day - 3. day & 4.7 vs. 5.6 & 0.9 & 16 & 112 & \multicolumn{4}{|c|}{ Data not available } \\
\hline & $>3$ days & 5.6 vs. 6.9 & 1.3 & 19 & 77 & \multicolumn{4}{|c|}{ Data not available } \\
\hline & 1. day-30. day & \multicolumn{4}{|c|}{ Data not available } & 4.8 vs. $5.4^{\mathrm{a}}$ & 0.6 & 12 & 167 \\
\hline & $>30$ days & \multicolumn{4}{|c|}{ Data not available } & 5.3 vs. $6.6^{\mathrm{a}}$ & 1.3 & 20 & 77 \\
\hline & STEMI & 10.0 vs. 12.4 & 2.4 & 19 & 42 & 9.4 vs. 10.8 & 1.4 & 13 & 71 \\
\hline & NSTEMI or UA & 9.9 vs. 12.1 & 2.2 & 18 & 46 & 10.1 vs. 12.3 & 2.2 & 18 & 46 \\
\hline & NSTEMI & \multicolumn{4}{|c|}{ Data not available } & 11.4 vs. 13.9 & 2.5 & 17 & 40 \\
\hline & UA & \multicolumn{4}{|c|}{ Data not available } & 8.6 vs. 9.1 & 0.5 & 5 & 200 \\
\hline & Diabetes & 12.2 vs. 17.0 & 4.8 & 28 & 21 & 14.1 vs. 16.2 & 2.1 & 12 & 48 \\
\hline & History of stroke/TIA & 19.1 vs. 14.4 & -4.7 & - & - & 19.0 vs. 20.8 & 1.8 & 8 & 56 \\
\hline & Age $<65$ years & 8.1 vs. 10.6 & 2.5 & 24 & 40 & 7.2 vs. 8.5 & 1.3 & 15 & 77 \\
\hline & Age $\geq 75$ years & 17.2 vs. 18.3 & 1.1 & 6 & 91 & 16.8 vs. 18.3 & 1.5 & 8 & 67 \\
\hline & Body mass $<60 \mathrm{~kg}$ & \multicolumn{4}{|c|}{ Data not available } & 13.1 vs. 17.3 & 4.2 & 24 & 24 \\
\hline & $\mathrm{CrCl}<60 \mathrm{ml} / \mathrm{min}$ & 15.1 vs. 17.5 & 2.4 & 14 & 42 & 17.3 vs. 22.0 & 4.7 & 21 & 22 \\
\hline & $2^{\text {nd }}$ event & 10.8 vs. 15.4 & 4.6 & 30 & 22 & \multicolumn{4}{|c|}{ Data not available } \\
\hline $\begin{array}{l}\text { Death from cardio- } \\
\text { vascular causes }\end{array}$ & Total & 2.1 vs. 2.4 & 0.3 & 13 & 334 & 4.0 vs. $5.1^{\mathrm{a}}$ & 1.1 & 21 & 91 \\
\hline Death from any cause & Total & 3.0 vs. 3.2 & 0.2 & 6 & 500 & 4.5 vs. $5.9^{a}$ & 1.4 & 23 & 72 \\
\hline $\begin{array}{l}\text { Heart attack without } \\
\text { fatal outcome }\end{array}$ & Total & 7.3 vs. $9.5^{\mathrm{a}}$ & 2.2 & 23 & 46 & 5.8 vs. $6.9^{\mathrm{a}}$ & 1.1 & 16 & 91 \\
\hline Non-fatal stroke & Total & 1.0 vs. 1.0 & 0 & 0 & - & 1.5 vs. 1.3 & -0.2 & - & - \\
\hline Urgent TVR & Total & 2.5 vs. $3.7^{\mathrm{a}}$ & 1.2 & 32 & 84 & \multicolumn{4}{|c|}{ Data not available } \\
\hline \multirow[t]{5}{*}{ Stent thrombosis } & $\begin{array}{l}\text { Complete (diagnosis certa- } \\
\text { in + probable) }\end{array}$ & 1.1 vs. $2.4^{\mathrm{a}}$ & 1.3 & 54 & 77 & 2.2 vs. $2.9^{\mathrm{a}}$ & 0.7 & 24 & 143 \\
\hline & $\begin{array}{l}\text { Complete (certain dia- } \\
\text { gnosis) }\end{array}$ & \multicolumn{4}{|c|}{ Data not available } & 1.3 vs. $1.9^{\mathrm{a}}$ & 0.6 & 33 & 167 \\
\hline & STEMI (certain diagnosis) & 1.1 vs. 2.4 & 1.2 & 50 & 84 & 1.6 vs. 2.4 & 0.8 & 33 & 125 \\
\hline & $\begin{array}{c}\text { Diabetes (diagnosis certain } \\
+ \text { + probable) }\end{array}$ & 2.0 vs. 3.6 & 1.6 & 44 & 63 & \multicolumn{4}{|c|}{ Data not available } \\
\hline & Diabetes (certain diagnosis) & \multicolumn{4}{|c|}{ Data not available } & 1.6 vs. 2.4 & 0.8 & 33 & 125 \\
\hline
\end{tabular}

ap $<0.05$

Abbreviations: ARR, absolute risk reduction; NNT, numer needed to treat; NSTEMI, non-ST-elevated myocardial infarction; RRR, relative risk reduction; STEMI, ST-elevated myocardial infarction; TIA, transient ischemic attack; TVR, target vessel revascularisation; UA, unstable angina; other — see Table 1

by correspondence (7\%). Only $10 \%$ of respondents had follow-up visits in the hospital or at the clinic. They also note that after the end of the inpatient phase of the study, ticagrelor or prasugrel was prescribed by the attending physician, the patient had to purchase the drug on their own, and no specific method of assessing compliance with these recommendations was reported.

Additionally, they argue that the study results could have been influenced by the ITT (intention-to-treat) method of analysis, which included all patients, depending on the group to which they were randomly assigned, regardless of whether they received the intervention or not. In ISAR-REACT 5, 410 of 2012 (20.4\%) and 410 of 2006 (20.4\%) patients in the ticagrelor and prasugrel groups, respectively, were discharged from the hospital without a randomized P2Y12 inhibitor. In addition, a further 243 patients in the ticagrelor group and 199 in the prasugrel group discontinued the prescribed antiplatelet drug after discharge from the hospital. A further 19 and 18 patients in each group were lost to follow-up. As a consequence, as many as 1299 patients who were not treated with the prescribed drug were included in the final analysis.

The supporters of the ISAR-REACT 5 study indicate that the open nature of the study and the follow-up visits in the form of telephone calls may constitute its strength and reflect conditions closer to everyday clinical practice. According to them, the mentioned method of ITT analysis is widely accepted and used in clinical trials, and the percentage of patients treated with prasugrel and ticagrelor, who were enrolled in the study, was comparable in the groups.

The views of opponents and supporters of the ISAR-REACT 5 study necessitate in-depth reflection as well as further detailed validation of the results obtained. However, it should be emphasized, that the study was carried out by an experienced and very reputable group of researchers, published in the most prestigious medical journal in the world, and taken into account when establishing the ESC guidelines.

Very good results of prasugrel treatment in patients undergoing primary $\mathrm{PCl}$ in the course of STEMI were found 
Table 3. Risk factors for stent thrombosis $[10,22]$

\begin{tabular}{|c|c|c|}
\hline Clinical factors & Angiographic factors & Factors related to the procedure \\
\hline Diabetes & Long lesions & Implantation of $\geq 3$ stents \\
\hline Chronic kidney disease & Small vessel diameter & Total length of stents $>60 \mathrm{~mm}$ \\
\hline Acute coronary syndrome & $\geq 3$ lesions & $\begin{array}{l}\text { History of complex revascularization (left coronary trunk, } \\
\text { stenting bifurcation with implantation of } \geq 2 \text { stents, } \\
\text { chronic total occlusion of the artery, stenting of the last } \\
\text { patent vessel) }\end{array}$ \\
\hline $\begin{array}{l}\text { Smoking } \\
\text { Reduced left ventricular ejection fraction }\end{array}$ & Venous bypass & Stent underexpansion \\
\hline Malignant tumor & Chronic obstruction & Marginal dissection \\
\hline Advanced age & Bifurcation & Malapposition \\
\hline Thrombocythemia & Massive calcification & Rupture of the stent span \\
\hline History of stent thrombosis during antiplatelet therapy & Left coronary trunk or proximal LAD & Overlapping stents \\
\hline Premature termination of DAPT & & Incomplete stent coverage of the lesion \\
\hline Resistance to DAPT & & Reduced TIMI flow after surgery \\
\hline
\end{tabular}

Abbreviations: DAPT, dual antiplatelet therapy; LAD, left anterior descending; TIMI, thrombolysis in myocardial infarction

in a registry study among 89000 patients. English patients were treated in 2007-2014 with prasugrel, clopidogrel, or ticagrelor. In the analysis of 30-day and 1-year mortality after using the propensity score matching method and the multivariate logistic regression method, the lowest 30-day and 1-year mortality was statistically significantly demonstrated in the population of patients treated with prasugrel compared to the groups treated with ticagrelor and clopidogrel. Mortality in patients receiving ticagrelor and clopidogrel was similar [20].

The latest 2020 network meta-analysis by Navarese et al., including 52,816 patients from 12 randomized trials, also compared the efficacy and safety profile of prasugrel, ticagrelor, and clopidogrel in ACS. It demonstrated that the results of the ISAR-REACT 5 study were significantly different from the results of the remaining 11 studies included in the analysis and, due to the existing limitations in the study methodology, should be interpreted with caution [21].

The authors of the meta-analysis showed that, compared to clopidogrel, ticagrelor significantly reduced cardiovascular mortality $(\mathrm{HR}, 0.82 ; 95 \% \mathrm{Cl}, 0.72-0.92)$ and all-cause mortality (HR, $0.83 ; 95 \% \mathrm{Cl}, 0.75-0.92)$, while such an effect on the reduction of both endpoints was not found for prasugrel (respectively: $\mathrm{HR}, 0.90 ; 95 \% \mathrm{Cl}, 0.80-1.01$ and $\mathrm{HR}, 0.92 ; 95 \% \mathrm{Cl}, 0.84-1.02)$. The comparison of the two strong inhibitors of the $\mathrm{P} 2 \mathrm{Y} 12$ receptor showed no significant differences in terms of the effect on both types of mortality (HR, 1.10; 95\% Cl, 0.94-1.29 and HR, 1.12; 95\% Cl, 0.98-1.28) [21].

Compared to clopidogrel, prasugrel significantly reduced the risk of myocardial infarction $(\mathrm{HR}, 0.81 ; 95 \% \mathrm{Cl}$, $0.67-0.98)$, while ticagrelor did not reduce this risk ( $\mathrm{HR}, 0.97$; $95 \% \mathrm{Cl}, 0.78-1.22)$. In contrast, the differences in effect on this endpoint between prasugrel and ticagrelor were not statistically significant.

Both ticagrelor and prasugrel significantly reduced the risk of stent thrombosis compared to clopidogrel, but prasugrel was associated with a significantly lower risk of stent thrombosis than ticagrelor (HR, 0.68; 95\% Cl, 0.50-0.93). In terms of the effect on the risk of bleeding, no statistically significant differences were found between prasugrel and ticagrelor (HR, 0.99; 95\% Cl, 0.79-1.24) [21].

\section{THERAPY WITH P2Y12 PLATE INHIBITORS IN PATIENTS WITH ACUTE CORONARY SYNDROME}

\section{Risk assessment of in-stent thrombosis}

Most cases of in-stent thrombosis occur within 30 days of $\mathrm{PCl}(70 \%-80 \%)$. Compared to in-stent restenosis, thrombosis is a much less frequent phenomenon; however, it is associated with very serious prognostic consequences. With the current practice of dual antiplatelet therapy and optimizing stent expansion with high-pressure inflation under the control of intravascular imaging, the incidence of thrombosis has significantly decreased: to $0.7 \%$ in the first year and approximately $0.2 \%-0.6 \%$ in the following year. This rate is lower for elective percutaneous intervention $(0.3 \%-0.5 \%)$ compared to acute coronary syndrome (3.4\%).

The clinical presentation of in-stent thrombosis is most often a recent myocardial infarction with ST-segment elevation, re-infarction, and in the case of stent thrombosis in a left coronary artery or the only permeable vessel, it is sudden cardiac death most often. The mortality rate in STEMI, caused by stent thrombosis, is significantly higher than that caused by de novo vessel closure and can be as high as $45 \%$. As many as $20 \%$ of patients with a history of stent thrombosis experience another episode during a follow-up. The greatest risk of in-stent thrombosis concerns patients with multiple clinical, angiographic, and procedural risk factors (Table 3) [10, 22].

\section{Risk assessment of hemorrhagic complications}

Major bleeding is associated with increased mortality in ACS. Therefore modern antiplatelet therapy must be based on both ischemic and bleeding complications assessment. The major and minor criteria for high bleeding risk during 
Table 4. Major and minor criteria for high risk of bleeding during percutaneous coronary intervention according to the Academic Research Consortium for High Risk (the risk of bleeding is high if $\geq 1$ main criterion or 2 lower criteria are met) [23]

\begin{tabular}{|c|c|}
\hline Main & Minor \\
\hline Envisaged use of long-term OAC & Age $\geq 75$ years \\
\hline Severe or end-stage CKD (eGFR $\left.<30 \mathrm{ml} / \mathrm{min} / 1.73 \mathrm{~m}^{2}\right)$ & Moderate CKD (eGFR 30-59 ml/min/1.73 m²) \\
\hline Hemoglobin $<11 \mathrm{~g} / \mathrm{dl}$ & Hemoglobin $11-12.9 \mathrm{~g} / \mathrm{dl}$ in men or $11-11.9 \mathrm{~g} / \mathrm{dl}$ in women \\
\hline $\begin{array}{l}\text { Spontaneous bleeding requiring hospitalization and/or blood transfusion within the } \\
\text { last } 6 \text { months or at any time if repeated }\end{array}$ & $\begin{array}{l}\text { Spontaneous bleeding requiring hospitalization and/or blood trans- } \\
\text { fusions in the last } 12 \text { months that do not meet the main criterion }\end{array}$ \\
\hline 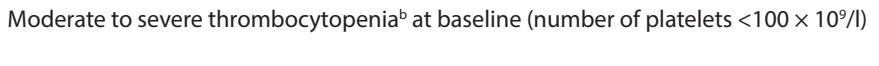 & $\begin{array}{l}\text { Chronic use of oral non-steroidal anti-inflammatory drugs or } \\
\text { steroids }\end{array}$ \\
\hline Chronic hemorrhagic diathesis & $\begin{array}{l}\text { Any ischemic stroke (ever history) that does not meet the main } \\
\text { criterion }\end{array}$ \\
\hline \multicolumn{2}{|l|}{ Cirrhosis of the liver with portal hypertension } \\
\hline \multicolumn{2}{|l|}{$\begin{array}{l}\text { Active malignant neoplasmc (excluding skin malignant neoplasm other than melano- } \\
\text { ma) in the last } 12 \text { months }\end{array}$} \\
\hline \multicolumn{2}{|l|}{$\begin{array}{l}\text { Spontaneous intracranial bleeding (ever before) } \\
\text { Traumatic intracranial bleeding within the last } 12 \text { months } \\
\text { The presence of arteriovenous malformation intracranial } \\
\text { Moderate to severe ischemic stroke }{ }^{d} \text { within the last } 6 \text { months }\end{array}$} \\
\hline $\begin{array}{l}\text { Recent major surgery or major trauma in the } 30 \text { days prior to } \mathrm{PCl} \\
\text { Major, irreversible surgery on DAPT }\end{array}$ & \\
\hline
\end{tabular}

the percutaneous coronary intervention can be assessed according to the Academic Research Consortium for High Bleeding Risk (ARC-HBR) definition, which was recently developed to ensure uniform risk stratification in clinical trials assessing the safety and efficacy of drug regimens in patients undergoing $\mathrm{PCl}$ [23]. The proposed ARC-HBR scale reflects a pragmatic approach that considers the latest studies in patients at high risk of bleeding, previously excluded from clinical trials on the duration or intensity of dual antiplatelet therapy (Table 4) [10, 23].

\section{Acute myocardial infarction with ST-segment elevation}

Limited data are available on when to initiate treatment with a P2Y12 inhibitor in patients with STEMI. Although there is no evidence of a clinical benefit of prior P2Y12 inhibitor administration, early initiation of $\mathrm{P} 2 \mathrm{Y} 12$ inhibitor therapy during patient transport to a primary $\mathrm{PCl}$ center remains a common practice in Europe and is consistent with pharmacokinetic data. Moreover, the available data indicate that the earliest possible administration of the drug may be preferred to obtain early treatment efficacy, especially in the event of long delays. However, in the cases where the diagnosis of STEMI is uncertain, there is a suspicion of mechanical complications of myocardial infarction or dissection of the ascending aorta, or when there is an increased risk of hemorrhagic complications, consideration should be given to delaying P2Y12 inhibitor administration until the anatomy of changes in the coronary arteries is known [7]. In the periprocedural (before or at the time of $\mathrm{PCl}$ ) and postoperative period, the preferred $\mathrm{P} 2 \mathrm{Y} 12$ platelet receptor inhibitors in patients undergoing primary $\mathrm{PCl}$ are prasugrel (loading dose $60 \mathrm{mg}$, maintenance dose $10 \mathrm{mg}$ once daily) and ticagrelor (loading dose $180 \mathrm{mg}$, maintenance dose $90 \mathrm{mg}$ twice daily). These drugs are characterized by a faster onset of action, greater potency, and better clinical outcomes than clopidogrel (loading dose $600 \mathrm{mg}$, maintenance dose $1 \times 75 \mathrm{mg} /$ day), which is used only when the above drugs are unavailable, not tolerated, or contraindicated (class of recommendation I, data reliability $A)[7,12,13]$.

Treatment with prasugrel or ticagrelor in combination with ASA should be continued for 12 months unless there is a contraindication or an excessive risk of bleeding. The doses of P2Y12 platelet inhibitors in patients undergoing primary $\mathrm{PCl}$ or not receiving reperfusion therapy are a $60 \mathrm{mg}$ loading dose for prasugrel, followed by a $10 \mathrm{mg} /$ day maintenance dose, and a $180 \mathrm{mg}$ loading dose for ticagrelor, followed by a 90 mg maintenance dose twice daily.

Prasugrel is contraindicated in patients after a previous stroke and/or a transient ischemic attack (TIA) event and is generally not recommended for use in patients $\geq 75$ years of age and in patients with lower body weight $(<60 \mathrm{~kg})$ because prasugrel treatment was not associated with a net clinical benefit in these subgroups of patients. If prasugrel is used in these patients, a lower dose $(5 \mathrm{mg})$ is recommended [24]. Prasugrel and ticagrelor should not be used in patients after a previous hemorrhagic stroke, in patients receiving oral anticoagulants, or in patients with moderate to severe liver disease [7].

\section{Acute myocardial infarction without ST-segment elevation}

Initial therapy defines the strategy by which antiplatelet agents are administered before coronary angiography and when the anatomy of the coronary arteries is unknown [25]. Although the rationale for such treatment in NSTEMI may seem obvious - obtaining sufficient platelet inhibition 
during $\mathrm{PCl}$ - there are no large-scale randomized trials that would support the routine strategy of initial treatment with clopidogrel or the strong inhibitors of the P2Y12 receptor — prasugrel and ticagrelor [10]. In relation to the data on pretreatment with ticagrelor, the previously mentioned ISAR-REACT 5 study demonstrated the superiority of the prasugrel selection strategy with the deferment of drug loading until coronary anatomy in NSTEMI patients is known over the ticagrelor selection strategy involving routine pre-loading. Importantly, this study did not show a clear benefit of the initial drug administration strategy (in this case, ticagrelor) [17].

Based on the available evidence, it is not recommended to routinely pre-administer a $\mathrm{P} 2 \mathrm{Y} 12$ receptor inhibitor in patients with NSTEMI, unknown coronary anatomy, and planned early invasive management $[17,26]$. In patients qualified for a delayed invasive strategy, initial treatment with a P2Y12 receptor inhibitor may be considered in selected cases and depending on these patients' risk of bleeding. Due to the lack of data indicating a beneficial effect of prasugrel in patients with ACS treated conservatively, it seems that ticagrelor should be used here [27].

The recommended standard of treatment with strong inhibitors of P2Y12 receptor (ticagrelor or prasugrel) is associated with the choice of drugs with a rapid onset of action, which enables their loading doses to be administered after diagnostic coronary angiography and immediately before $\mathrm{PCl}$. It is worth noting that the routine strategy of initial drug loading may prove detrimental to a significant percentage of patients with a diagnosis other than NSTEMI (e.g. with aortic dissection or hemorrhagic complications including intracranial bleeding) and may increase the risk of bleeding or delay the performance of procedures in patients referred to CABG after diagnostic angiography [10].

In patients with NSTEMI, DAPT, including ASA and a strong inhibitor of $\mathrm{P} 2 \mathrm{Y} 12$ receptor, prasugrel, or ticagrelor (class of recommendation I, evidence level B) are recommended $[10,12,13]$. Clopidogrel should only be used when prasugrel or ticagrelor is unavailable, intolerable, or contraindicated, or in patients requiring oral anticoagulation $[10,28]$.

In patients with NSTE-ACS qualified for coronary angioplasty, according to the guidelines, the administration of prasugrel should be considered with preference to ticagrelor (class of recommendations lla, level of evidence B) $[10,17]$.

In guidelines, the initiation of $\mathrm{P} 2 \mathrm{Y} 12$ inhibitor treatment is determined on the basis of time intervals in which the drug was assessed in the registration studies, i.e. for ticagrelor and clopidogrel: the initiation of therapy as soon as possible and safe or for prasugrel: after the indication for $\mathrm{PCl}$ based on the anatomy of the coronary arteries. Prasugrel is given as a $60 \mathrm{mg}$ loading dose, then $10 \mathrm{mg} /$ day in combination with ASA. A maintaining dose of $5 \mathrm{mg}$ is recommended for patients weighing less than $60 \mathrm{~kg}$. In patients over the age of 75 years, prasugrel is generally not recommended, but if deemed necessary, the $5 \mathrm{mg}$ dose should be used. Platelet receptor P2Y12 inhibitor is recommended in combination with ASA for 12 months unless there are contraindications or an excessive risk of bleeding [8-10, 13, 14, 29].

\section{THERAPY WITH P2Y12 PLATELET RECEPTOR INHIBITORS IN PATIENTS WITH CHRONIC CORONARY SYNDROME}

In patients with chronic coronary syndrome (CCS) undergoing elective $\mathrm{PCl}$, the recommended dose of clopidogrel is $75 \mathrm{mg} /$ day following a loading dose (e.g. $600 \mathrm{mg}$ or $>5$ days of maintenance therapy) as an adjunct to ASA for 6 months after coronary artery stent implantationt, regardless of the type of stent, unless a shorter treatment (1-3 months) is indicated due to the risk or occurrence of life-threatening bleeding (class of recommendation I, level of evidence A) $[8,30]$. Prasugrel or ticagrelor may be considered, at least as an initial treatment, in the special cases with a high risk of stent thrombosis, or in the cases where thrombosis may have serious clinical consequences (implantation of a stent into a trunk of the left main coronary artery, a proximal part of the anterior descending artery or the last unobstructed coronary artery, suboptimal stent implantation, total stent length $>60 \mathrm{~mm}$, diabetes mellitus, chronic kidney disease, implantation of two stents into a branch of a coronary artery, the opening of a chronically occluded coronary artery, a history of stent thrombosis despite adequate anticoagulation) or if DAPT cannot be used due to ASA intolerance (class of recommendation Ilb, level of evidence C) [30].

\section{CHANGE OF THERAPY BETWEEN ORAL INHIBITORS OF PLATE RECEPTORS P2Y12}

In the document "Updated position of the ESC on the use of dual antiplatelet therapy in coronary artery disease in 2017, prepared in cooperation with EACTS," for the first time, the possibility and method of switching treatment between oral inhibitors of platelet receptors P2Y12 was clearly defined [8]. Switching from clopidogrel to ticagrelor is the only change between P2Y12 antagonists that has been analyzed in a power-appropriate study to evaluate a clinical endpoint. The study was not specifically designed to assess the safety and efficacy of switching from clopidogrel to ticagrelor. In the PLATO trial, almost $50 \%$ of patients randomized to the ticagrelor group were pretreated with clopidogrel and mostly received a loading dose of 300-600 mg [13]. No changes in the efficacy and safety of ticagrelor were observed with previous clopidogrel administration [31]. On the other hand, in the TRITON-TIMI 38 study, it was determined that the earlier intake of the $\mathrm{P} 2 \mathrm{Y} 12$ receptor antagonist by patients should be a criterion for exclusion from the study [12]. Registry data provide reassuring information on the safety profile of switching from clopidogrel to prasugrel [32-34], but there are no results from adequately powered randomized 


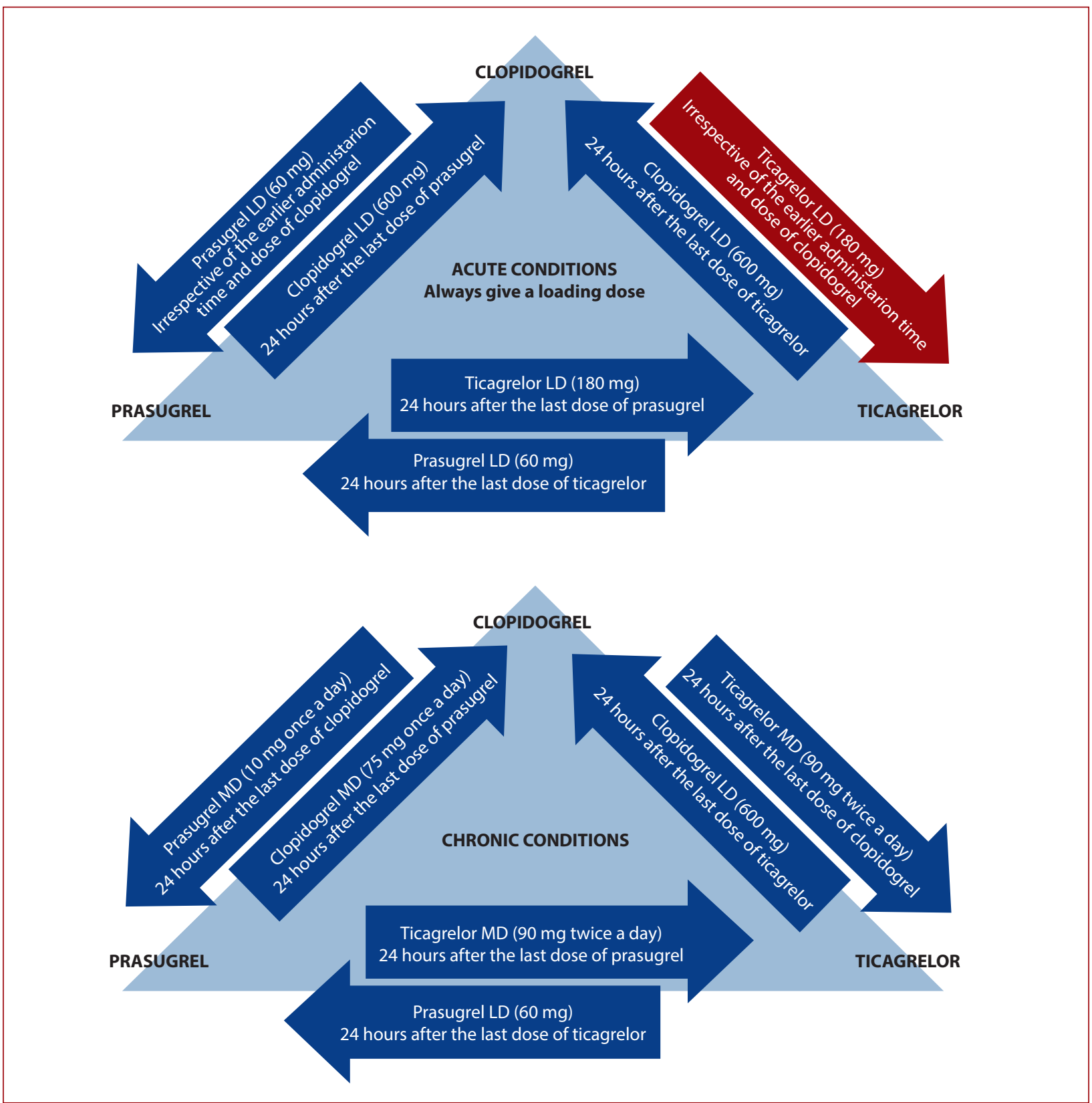

Figure 1. Treatment change algorithm within the group of $\mathrm{P} 2 \mathrm{Y} 12$ inhibitors in acute and chronic conditions [8]. The individual colors refer to the class of recommendations of the European Society of Cardiology (ESC) (green - class I, orange - class Ilb). The green arrow from clopidogrel to ticagrelor identifies the only treatment conversion algorithm for which data from acute coronary syndromes studies are available. There are no treatment outcome data (the orange arrows) for other treatment switch algorithms. Switching treatment as part of hospitalization was considered in acute conditions

Abbrebiations: LD, loading dose; MD, maintenance dose

trials to evaluate the clinical endpoint. In ACS patients who have previously received clopidogrel, it is recommended to switch from clopidogrel to ticagrelor at a loading dose of $180 \mathrm{mg}$ in the early post-admission period, regardless of the time of intake and the loading dose of clopidogrel unless there are contraindications for ticagrelor (class of recommendation $\mathrm{I}$, data confidence level $\mathrm{B}$ ). In the event of adverse effects/intolerance to treatment, an additional switch of oral P2Y12 inhibitors may be considered following the algorithm proposed below (class of recommendations Ilb, level of evidence C) (Figure 1) [8].

It should be noted that an acute substitution should always be a loading dose. When switching from clopidogrel to prasugrel or ticagrelor, the loading dose is administered regardless of the earlier administration time and dose of clopidogrel. In chronic conditions, a substitution is also possible, but then the loading dose is valid only when replacing ticagrelor with prasugrel or with clopidogrel. However, in 
chronic conditions, there is always a 24-hour interval from the administration of the last dose of the previously used P2Y12 platelet receptor inhibitor.

\section{CHARACTERISTICS OF PATIENTS WHO CAN GET THE MOST BENEFIT FROM PRASUGREL THERAPY}

Prasugrel should be used in appropriately selected patients with a diagnosis of ACS. These are people who have no history of stroke, TIA, or active pathological bleeding. It should also be remembered that the dose should be adjusted in patients who are 75 years old and older and/or weigh less than $60 \mathrm{~kg}$.

Prasugrel should be used in patients with ACS undergoing primary or delayed $\mathrm{PCl}$. Compared to ticagrelor, it should be preferred in patients at increased risk of stent thrombosis. In patients with NSTEMI, the choice of a platelet receptor $\mathrm{P} 2 \mathrm{Y} 12$ inhibitor should be made after coronary angiography.

\section{CONCLUSION}

The daily practice of ACS treatment in Poland indicates that the guidelines in force for several years, which recommend the choice of prasugrel or ticagrelor over clopidogrel, are not widely used. Poland is still a "clopidogrel" country, which results mainly from the lack of reimbursement for the strong inhibitors of $\mathrm{P} 2 \mathrm{Y} 12$ platelet receptors recommended in the guidelines. Moreover, frequently the treatment with a modern inhibitor of P2Y12 platelet receptors, applied during hospitalization, is discontinued in the weeks or months after the ACS due to the financial limitations of Polish patients. It seems that at present the only way out of this situation is the introduction of generic drugs into armamentarium antiplatelet treatment of ACS, which will not only create an opportunity to change the current ACS treatment strategy but also reduce the still-too-high mortality rate within a year of an ACS episode.

\section{Article information}

Conflict of interest: Lecturer fees, participation in advisory bodies, clinical trials of antiplatelet drugs of the following manufacturers: MB - Gedeon Richter, Sanofi; JL — AstraZeneca, Gedeon Richter; ML - AstraZeneca, Gedeon Richter; SB — AstraZeneca, Gedeon Richter, Sanofi; AM - Gedeon Richter; BWK - AstraZeneca, Gedeon Richter, Sanofi; MG - AstraZeneca, Gedeon Richter; WW - AstraZeneca; AW - AstraZeneca, Gedeon Richter, Sanofi.

Open access: This article is available in open access under Creative Common Attribution-Non-Commercial-No Derivatives 4.0 International (CC BY-NC-ND 4.0) license, allowing to download articles and share them with others as long as they credit the authors and the publisher, but without permission to change them in any way or use them commercially. For commercial use, please contact the journal office at kardiologiapolska@ptkardio.pl.

\section{REFERENCES}

1. World Health Organization. Cardiovascular diseases (CVDs). Available online: www.who.int/mediacentre/factsheets/fs317/en/. (Accessed: January 1, 2022).
2. Townsend N, Nichols M, Scarborough $P$, et al. Cardiovascular disease in Europe - epidemiological update 2015. Eur Heart J. 2015; 36(40): 26962705, doi: 10.1093/eurheartj/ehv428, indexed in Pubmed: 26306399.

3. Poloński L, Gierlotka M, Zdrojewski T. The Nationwide Acute Myocardial Infarction Database AMI-PL and the Polish Registry of Acute Coronary Syndromes PL-ACS [article in Polish]. Medycyna Praktyczna, Kraków 2015.

4. National Health Fund (NFZ) about health. Ischemic heart disease [article in Polish], Warszawa 2020.

5. Gierlotka M, Zdrojewski T, Wojtyniak B, et al. Incidence, treatment, in-hospital mortality and one-year outcomes of acute myocardial infarction in Poland in 2009-2012 - nationwide AMI-PL database. Kardiol Pol. 2015; 73(3): 142-158, doi: 10.5603/KP.a2014.0213, indexed in Pubmed: 25371307.

6. Mozaffarian D, Benjamin EJ, Go AS, et al. Writing Group Members, American Heart Association Statistics Committee, Stroke Statistics Subcommittee. Heart disease and stroke statistics-2016 update: a report from the American Heart Association. Circulation. 2016; 133(4): e38-360, doi: 10.1161/CIR.0000000000000350, indexed in Pubmed: 26673558.

7. Ibanez B, James S, Agewall S, et al. 2017 ESC guidelines for the management of acute myocardial infarction in patients presenting with ST-segment elevation [article in Polish]. Kardiol Pol. 2018; 76(2): 229-313, doi: 10.5603/kp.2018.0041, indexed in Pubmed: 29457615.

8. Valgimigli $M$, Bueno $H$, Byrne R, et al. 2017 ESC focused update on dual antiplatelet therapy in coronary artery disease developed in collaboration with EACTS [article in Polish]. Kardiol Pol. 2017; 75(12): 1217-1299, doi: 10.5603/kp.2017.0224, indexed in Pubmed: 29251754.

9. Neumann FJ, Sousa-Uva M, Ahlsson A, et al. 2018 ESC/EACTS Guidelines on myocardial revascularization [article in Polish]. Kardiol Pol. 2018; 76(12): 1585-1664, doi: 10.5603/kp.2018.0228, indexed in Pubmed: 30566213.

10. Collet JP, Thiele H, Barbato E, et al. 2020 ESC Guidelines for the management of acute coronary syndromes in patients presenting without persistent ST-segment elevation. Eur Heart J. 2021 Apr 7;42(14):12891367, doi: 10.1093/eurheartj/ehaa575, indexed in Pubmed: 32860058.

11. Rakowski T, Siudak Z, Dziewierz A, et al. Contemporary use of P2Y inhibitors in patients with ST-segment elevation myocardial infarction referred to primary percutaneous coronary interventions in Poland: data from ORPKI national registry. J Thromb Thrombolysis. 2018;45(1): 151-157, doi: 10.1007/s11239-017-1579-9, indexed in Pubmed: 29075924.

12. Wiviott $S$, Braunwald E, McCabe $C$, et al. Prasugrel versus clopidogrel in patients with acute coronary syndromes. N Engl J Med. 2007; 357(20): 2001-2015, doi: 10.1056/nejmoa0706482, indexed in Pubmed: 17982182.

13. Wallentin L, Becker RC, Budaj A, et al. PLATO Investigators. Ticagrelor versus clopidogrel in patients with acute coronary syndromes. N Engl J Med. 2009; 361(11): 1045-1057, doi: 10.1056/NEJMoa0904327, indexed in Pubmed: 19717846.

14. Wiviott SD, Braunwald E, Angiolillo DJ, et al. TRITON-TIMI 38 Investigators. Greater clinical benefit of more intensive oral antiplatelet therapy with prasugrel in patients with diabetes mellitus in the trial to assess improvement in therapeutic outcomes by optimizing platelet inhibition with prasugrel-Thrombolysis in Myocardial Infarction 38. Circulation. 2008; 118(16): 1626-1636, doi: 10.1161/CIRCULATIONAHA.108.791061, indexed in Pubmed: 18757948.

15. Montalescot G, Wiviott SD, Braunwald E, et al. TRITON-TIMI 38 investigators. Prasugrel compared with clopidogrel in patients undergoing percutaneous coronary intervention for ST-elevation myocardial infarction (TRITON-TIMI 38): double-blind, randomised controlled trial. Lancet. 2009; 373(9665): 723-731, doi: 10.1016/S0140-6736(09)60441-4, indexed in Pubmed: 19249633.

16. Motovska $\mathrm{Z}$, Hlinomaz $\mathrm{O}$, Miklik R, et al. Prasugrel versus ticagrelor in patients with acute myocardial infarction treated with primary percutaneous coronary intervention: multicenter randomized PRAGUE-18 study. Circulation. 2016; 134(21): 1603-1612, doi: 10.1161/circulationaha.116.024823.

17. Schüpke S, Neumann FJ, Menichelli M, et al. ISAR-REACT 5 Trial Investigators. Ticagrelor or prasugrel in patients with acute coronary syndromes. $\mathrm{N}$ Engl J Med. 2019; 381(16): 1524-1534, doi: 10.1056/NEJMoa1908973, indexed in Pubmed: 31475799.

18. Ostrowska M, Adamski P, Kubica J. The ISAR-REACT trial: Should it change clinical practice? [article in Polish]. Folia Cardiol. 2019; 14(5):483-487, doi: 10.5603/FC.a2019.0099. 
19. Kubica J, Jaguszewski M. ISAR-REACT 5 - What have we learned? Cardiol J. 2019; 26(5): 427-428, doi: 10.5603/CJ.a2019.0090, indexed in Pubmed: 31536136.

20. Olier I, Sirker A, Hildick-Smith DJR, et al. British Cardiovascular Intervention Society and the National Institute for Cardiovascular Outcomes Research. Association of different antiplatelet therapies with mortality after primary percutaneous coronary intervention. Heart. 2018; 104(20): 1683-1690, doi: 10.1136/heartjnl-2017-312366, indexed in Pubmed: 29437885.

21. Navarese EP, Khan SU, Kołodziejczak M, et al. Comparative efficacy and safety of oral P2Y inhibitors in acute coronary syndrome: network meta-analysis of 52816 patients from 12 randomized trials. Circulation. 2020; 142(2): 150-160, doi: 10.1161/CIRCULATIONAHA.120.046786, indexed in Pubmed: 32468837.

22. Kuramitsu S, Sonoda S, Ando K, et al. Drug-eluting stent thrombosis: current and future perspectives. Cardiovasc Interv Ther. 2021; 36(2): 158-168, doi: 10.1007/s12928-021-00754-x, indexed in Pubmed: 33439454.

23. Urban $P$, Mehran R, Colleran $R$, et al. Defining high bleeding risk in patients undergoing percutaneous coronary intervention: a consensus document from the Academic Research Consortium for High Bleeding Risk. Eur Heart J. 2019; 40(31): 2632-2653, doi: 10.1093/eurheartj/ehz372, indexed in Pubmed: 31116395.

24. Roe MT, Armstrong PW, Fox KAA, et al. TRILOGY ACS Investigators. Prasugrel versus clopidogrel for acute coronary syndromes without revascularization. N Engl J Med. 2012; 367(14): 1297-1309, doi: 10.1056/NEJMoa1205512, indexed in Pubmed: 22920930.

25. Sibbing D, Kastrati A, Berger PB. Pre-treatment with P2Y12 inhibitors in ACS patients: who, when, why, and which agent? Eur Heart J. 2016; 37(16): 1284-1295, doi: 10.1093/eurheartj/ehv717, indexed in Pubmed: 26712838.

26. Montalescot G, Bolognese L, Dudek D, et al. ACCOAST Investigators. Pretreatment with prasugrel in non-ST-segment elevation acute coronary syndromes. N Engl J Med. 2013; 369(11): 999-1010, doi: 10.1056/NEJMoa1308075, indexed in Pubmed: 23991622.

27. Lindholm D, Varenhorst C, Cannon CP, et al. Ticagrelor vs. clopidogrel in patients with non-ST-elevation acute coronary syndrome with or without revascularization: results from the PLATO trial. Eur Heart J. 2014; 35(31): 2083-2093, doi: 10.1093/eurheartj/ehu160, indexed in Pubmed: 24727884.
28. Mehta S, Yusuf S, Peters R, et al. Effects of pretreatment with clopidogrel and aspirin followed by long-term therapy in patients undergoing percutaneous coronary intervention: the PCI-CURE study. Lancet. 2001; 358(9281): 527-533, doi: 10.1016/s0140-6736(01)05701-4, indexed in Pubmed: 11520521.

29. Yusuf S, Zhao F, Mehta SR, et al. Clopidogrel in Unstable Angina to Prevent Recurrent Events Trial Investigators. Effects of clopidogrel in addition to aspirin in patients with acute coronary syndromes without ST-segment elevation. NEngl J Med. 2001;345(7):494-502, doi: 10.1056/NEJMoa010746, indexed in Pubmed: 11519503.

30. Knuuti J, Wijns W, Saraste A, et al. 2019 ESC Guidelines for the diagnosis and management of chronic coronary syndromes. Eur Heart J.2020;41(3): 407-477, doi: 10.1093/eurheartj/ehz425, indexed in Pubmed: 31504439.

31. Cannon CP, Harrington RA, James S, et al. PLATelet inhibition and patient Outcomes Investigators. Comparison of ticagrelor with clopidogrel in patients with a planned invasive strategy for acute coronary syndromes (PLATO): a randomised double-blind study. Lancet. 2010; 375(9711): 283293, doi: 10.1016/S0140-6736(09)62191-7, indexed in Pubmed: 20079528.

32. Bagai A, Peterson ED, Honeycutt E, et al. In-hospital switching between adenosine diphosphate receptor inhibitors in patients with acute myocardial infarction treated with percutaneous coronary intervention: Insights into contemporary practice from the TRANSLATE-ACS study. Eur Heart J Acute Cardiovasc Care. 2015; 4(6): 499-508, doi: 10.1177/2048872614564082, indexed in Pubmed: 25515725.

33. Goldstein $\mathrm{P}$, Grieco $\mathrm{N}$, Ince $\mathrm{H}$, et al. MULTIPRAC study investigators. MULTInational non-interventional study of patients with ST-segment elevation myocardial infarction treated with PRimary Angioplasty and Concomitant use of upstream antiplatelet therapy with prasugrel or clopidogrel — the European MULTIPRAC Registry. Eur Heart J Acute Cardiovasc Care. 2015; 4(3): 220-229, doi: 10.1177/2048872614547449, indexed in Pubmed: 25182465 .

34. Alexopoulos D, Xanthopoulou I, Deftereos S, et al. In-hospital switching of oral P2Y12 inhibitor treatment in patients with acute coronary syndrome undergoing percutaneous coronary intervention: prevalence, predictors and short-term outcome. Am Heart J. 2014; 167(1): 68-76.e2, doi: 10.1016/j.ahj.2013.10.010, indexed in Pubmed: 24332144. 